\title{
S5ynthesis
}

International Scientific Conference of IT and Business-Related Research

\section{GRINFILD INVESTICIJE U SRBIJI I ZEMLJAMA U OKRUŽENJU U TRANZICIJI SA ASPEKTA INTERESA STRANIH INVESTITORA}

\author{
GREENFIELD INVESTMENTS IN SERBIA AND NEIGHBOURING TRANSITION COUNTRIES IN \\ RELATION TO FOREIGN INVESTORS' INTERESTS
}

\author{
Predrag Vukadinović, Goranka Knežević \\ Univerzitet Singidunum, Danijelova 32, Beograd, Srbija
}

\begin{abstract}
Apstrakt:
Strane direktne investicije svakako predstavljaju značajan faktor razvoja svake ekonomije, a naročito ekonomija u razvoju. Ovaj rad stavlja poseban naglasak na grinfild investicije u Srbiji i zemljama u tranziciji jugoistočne Evrope kao i na interes stranih investitora za realizaciju ovih investicija. Ova vrsta investicija je u fokusu rada pre svega zbog svojih karakteristika u pogledu uticaja na dugoročni ekonomski razvoj. Interes stranih investitora prikazan je najpre kroz kretanje stranih direktnih investicija na globalnom nivou, a naročito kroz realizaciju ovih investicija u Srbiji i zemljama u tranziciji jugoistočne Evrope, koristeći pri tome analizu više parametara koji ukazuju na interes stranih investitora. To se pre svega odnosi na broj i vrednost grinfild investicija kao i pet najznačajnijih sektora privrede kao odredište za ove investicije. Imajući u vidu da investitori donose odluke na osnovu procene rizika investiranja, u radu su prikazana četiri najznačajnija rizika koji imaju negativan uticaj na donošenje odluka kao i četiri rizika koja imaju najmanje negativan uticaj na donošenje investicionih odluka.
\end{abstract}

\section{Ključne reči:}

strane direktne investicije, grinfild investicije, jugoistočna Evropa, zemlje u tranziciji.

\section{UVOD}

Razvoj svake ekonomije počiva na mnogobrojnim faktorima uticaja. Strane direktne investicije (u daljem tekstu SDI) nisu jedini faktor razvoja ali svakako se mogu tretirati kao jedan od najznačajnijih faktora sa direktnim ali i indirektinim uticajem na razvoj ekonomije. Složenost i kompleksnost SDI se ne može posmatrati samo kroz prizmu ekonomskih efekata već i kroz činjenicu da dejstvo stranog kapitala uključuje i različite socijalne, političke i tehnološke uticaje (Cvetković, 2004). Istovremeno, priliv SDI zavisi i od otvorenosti država-zemalja koje su potencijalne destinacije SDI kao i od određenih rizika koje investitori procenjuju pre donošenja odluka o investiranju i zainteresovanosti za investiranje.

Grinfild investicije (u daljem tekstu GI), kao vrsta SDI, nedvosmisleno predstavljaju značajan činilac i faktor pokretanja privrednog razvoja, odnosno, može se sasvim sigurno reći da GI predstavljaju jedan od osnovnih pokretača privrednog rasta u mnogim zemljama u svetu a naročito u onim koje su u tranziciji (Begović et al., 2008). Sprovedena su mnogobrojna istraživanja o problemu privlačenja SDI, nezavisno od toga o kom stepenu razvoja ekonomije se radi. Tako je i određenim empirijskim modelima potvrđena pretpostavka da su otvorenost i veličina

\begin{abstract}
:
Foreign direct investments are certainly one of the essential factors of development of any economy, especially developing economies. This paper places an emphasis on green field investments in Serbia and transition countries of the southeastern Europe and the interests of foreign investors concerning the realization of these investments. The paper devotes special attention to this type of investments primarily due to their characteristics in terms of their impact on long-term economic development. The interests of foreign investors are shown primarily through the flow of foreign direct investments on a global level in general, and particularly the destination of these investments in Serbia and transition countries of southeastern Europe, using the statistical analysis of several indicators that point to the interests of foreign investors. This primarily refers to the number and value of green field investments, as well as the five most important sectors of the economy as an investment destination. Bearing in mind that investors make decisions based on the investment risk assessment, the four most significant risks with adverse effects on decision-making are given, along with four risks that have the least negative impact on making investment decisions.
\end{abstract}

\section{Key words:}

foreign direct investment, greenfield investments, southeastern Europe, transition countries.

tržišta zemlje destinacije SDI determinante privlačenja ovih investicija u nacionalnu privredu (Vidas-Bubanja, 1998).

Političke i ekonomske promene u svetu poslednjih decenija, a posebno imajući u vidu još uvek prisutnu svetsku ekonomsku krizu inicirale su i određene oblike političko-ekonomskih integracija, pre svega Evropsku uniju (u daljem tekstu EU) kao opredeljujući pravac daljeg puta Srbije i njene ekonomije. Pored Srbije, Albanija, Makedonija, Bosna i Hercegovina (u daljem tekstu BiH) i Crna Gora (u daljem tekstu CG) predstavljaju grupu zemalja u tranziciji, na putu ka članstvu u EU.

Bez obzira na slične političko-ekonomske aktivnosti svake od pomenutih zemalja i njihove napore koje čine na putu ka prijemu u članstvo u EU, interes stranih investitora u pogledu investiranja u obliku GI nije podjednak. Statistički pokazatelji, izraženi kroz broj i vrednost GI po destinacijama ukazuju na rang interesa kao i na procenu sigurnosti investiranja uzimajući u obzir razmatranu destinaciju. Investitori pokazuju različit stepen interesa i u smislu odabira sektora privrede i delatnosti u koje će investirati. Globalni pregled interesa investitora za ulaganja posmatran po sektorima privrede, može da bude dobar usmeravajući pokazatelj zemljama u tranziciji, kojim sektorima privrede i granama delatnosti treba da daju prioritet u stvaranju uslova ka atraktivnosti za određene destinacije investiranja. 
Veoma važan moment isticanja interesa stranih investitora u smeru investiranja je i procena rizika investiranja, sa stanovišta različitih vrsta rizika. U ovom radu istaknuti su najznačajniji rizici koji imaju najveći uticaj na interes za investiranjem kao i donošenje odluke o budućoj GI.

\section{REZULTATI I DISKUSIJA}

Globalni tok SDI ukazuje na varijacije u analiziranom petogodišnjem period (Tabela 1 ).

Nakon rasta SDI u periodu 2009-2011. godine, dolazi do pada ovih ivesticija u 2012. godini. Međutim, oporavak SDI je vidljiv u 2013. godini (rast od 9\%). Ovakav rast nakon 2012. godine ukazuje na oprezan optimizam u pogledu rasta SDI, pri čemu UNCTAD projektuje rast ovih investicija u periodu 2014-2016. godine uz napomenu da krhkost u nekim tržištima u razvoju, kao i rizici vezani za političku nesigurnost i regionalnu nestabilnost mogu negativno uticati na očekivani rast SDI (UNCTAD, 2014). Analiza posmatranog perioda ukazuje da se može uočiti pravilo rasta ovih investicija do 2011. godine, zatim pad u 2012. godini i oporavak u 2013. godini. Trend održanja većeg rasta SDI u zemljama u razvoju u odnosu na razvijene zemlje kao destinacije ovih investicija, nastavlja se i posle 2012 godine. Priliv ovih investicija u razvijene zemlje iznosio je 566 milijardi USD, odnosno 39\% ukupnog priliva na globalnom nivou, dok je priliv SDI u zemlje u razvoju dostigao iznos od 778 milijardi USD, odnosno 54\% globalnog priliva SDI. Zemlje u tranziciji, dostigle su nivo od 108 milijardi USD priliva ovih investicija, što predstavlja 7\% ukupnog-globalnog priliva SDI u 2013. godini. (UNCTAD, 2014)

Priliv SDI u Srbiji i zemljama u okruženju u tranziciji pokazuje drugačija kolebanja nego što je to pokazala analiza na globalnom nivou, u zavisnosti od zemlje do zemlje. Makedonija ima identično kretanje-priliv SDI, poredeći sa globalnim tokom SDI, dok druge zemlje u okruženju pokazuju kolebanje koje se u određenoj meri razlikuje u odnosu na uočeno pravilo kretanja SDI na globalnom nivou. BiH pokazuje rast priliva SDI u period 2009-2011. godine ali oporavak priliva nije zabeležen u 2013. godini nakon pada u 2012. godini. Albanija beleži rast priliva u 2009 i 2010. godini ali 2011-2012. godina je karakteristična po padu priliva, da bi se oporavak desio u 2013. godini i to čak za $43 \%$ više nego u prethodnoj godini, što predstavlja značajan skok priliva ovih investicija. Crna Gora pokazuje nešto drugačiji tok priliva SDI, tako što je pad ovih investicija zabeležen u periodu 2009-2011. godine., zatim oporavak priliva u 2012. godini što odstupa od uočenog pravila pada priliva u 2012. godini, da bi u 2013. godini, došlo do pada priliva ovih investicija za $27 \%$. Srbija beleži ciklično kretanje priliva SDI iz godine u godinu. Nakon 2009. godini, posle priliva od 1.958,6 milijardi USD dolazi do pada priliva u 2010. godini na $1.328,6$ milijardi USD, što je procentualni pad za $32 \%$. Oporavak priliva, zabeležen je u 2011. godini i to na nivo od 2.709,3 milijarde USD što predstavlja rast ptiliva za čak $132 \%$. Međutim, sledi nagli pad priliva u 2012. godini na 365,1 miliona USD, što je drastičan pad za skoro osam puta u odnosu na 2011. godinu Karakteristično je i to da je u 2013. godini došlo do suprotnog drastično različitog kretanja priliva SDI, kada je priliv porastao za oko tri puta, na 1.033,7 milijardi USD.

Dalja analiza tokova SDI biće koncentrisana na broj i vrednost grinfild projekata u Srbiji i zemljama u okruženju u tranziciji, što ukazuje na različitost interesa stranih investitora kada je u pitanju investiranje u zemljama u tranziciji. Ova različitost se ogleda u broju grinfild projekata (u daljem tekstu GP) i u njihovoj investiranoj vrednosti posmatrano od zemlje do zemlje. Naglasak na analizi GI polazi od stava da su glavne destinacije GI zemlje u razvoju i zemlje u tranziciji dok su glavni oblici SDI u razvijenim zemljama spajanja i pripijanja, odnosno akvizicije

\begin{tabular}{|l|r|r|r|r|r|}
\hline Region/država & 2009 & 2010 & 2011 & 2012 & 2013 \\
\hline Svet-ukupno & 1221840,1 & 1422254,8 & 1700082,4 & 1330272,9 & 1451965,4 \\
\hline Ekonomije u tranziciji & 70664,3 & 70573,1 & 94836,3 & 84159,4 & 107966,5 \\
\hline Jugo-Istočna Evropa & 5332,6 & 4242,2 & 5652,6 & 2593,5 & 3715,9 \\
\hline Makedonija & 201,4 & 211,9 & 468,2 & 92,6 & 333,9 \\
\hline Bosna i Hercegovina & 249,9 & 406,0 & 493,3 & 366,3 & 331,7 \\
\hline Albania & 995,9 & 1050,7 & 876,3 & 855,4 & 1225,5 \\
\hline Crna Gora & 1527,3 & 760,4 & 558,1 & 619,8 & 447,4 \\
\hline Srbija & 1958,8 & 1328,6 & 2709,3 & 365,1 & 1033,7 \\
\hline
\end{tabular}

Napomena: tabela sadrži podatke za ukupne SDI po vrstama (GI i akvizicije).

Tabela 1. Priliv SDI po regionima/državama (U milionima USD)

Izvor: http://unctad.org/SearchCenter/Pages/Results.aspx?k=FDI\%2FTNC\%20database

\begin{tabular}{|l|r|r|r|r|r|}
\hline Region/država & 2009 & 2010 & 2011 & 2012 & 2013 \\
\hline Ekonomije u tranziciji & 832 & 887 & 833 & 708 & 686 \\
\hline Jugo-Istočna Evropa & 107 & 134 & 178 & 190 & 181 \\
\hline Crna Gora & 1 & 7 & 6 & 8 & 7 \\
\hline Albania & 18 & 14 & 25 & 11 & 32 \\
\hline Makedonija & 20 & 21 & 30 & 25 & 25 \\
\hline Bosna i Hercegovina & 61 & 83 & 109 & 112 & 27 \\
\hline Srbija & & & 118 \\
\hline
\end{tabular}

Tabela 2. Broj grinfild projekata po destinacijama

Izvor: UNCTAD (2014) 
(M\&A), (Begović et al., 2008). Statistički pokazatelji, izraženi kao broj projekata, kao osnova analize prikazani su u Tabeli 2.

Napomenuto je već da pokazatelji iskazani u Tabeli 1. obuhvataju ukupnu vrednost SDI uključujući sve vrste ovih investicija. Cilj ovog istraživanja i analize u prvom redu je anliza samo GI, imajući u vidu njihove karakteristike kojima se sa stanovišta dužeg roka zadržavanja u ekonomiji jedne zemlje daje prednost.

Uočljivo je da je kretanja broja projekata GI u ekonomijama u tranziciji (prema kategorizaciji UNCTAD), rastuće u period 2009-2011. godine dok se u 2012 i 2013. godini beleži pad broja ovih projekata. Sužavajući analizu na zemlje u tranziciji u jugoistočnoj Evropi, vidljivo je odstupanje od prethodno uočenog pravila. Naime, kretanje broja projekata GI pokazuje rast u period 2009-2012. godine, dok je u 2013. godini zabeležen pad broja ovih projekata. Dublja analiza, usmerena na zemlje jugo-istočne Evrope u tranziciji ukazuje na različita kretanja ovih projekata iz godine u godinu, odnosno odstupanje od uočenog pravila na nivou regiona (jugo-istočna Evropa).

Crna Gora je imala u analiziranom period ukupno 27 projekata, s tim što ih je najviše bilo 2010. godini, dok u 2011. godini dolazi do naglog pada broja ovih projekata za 40\%. U 2012 i 2013. godini uočljiv je neznatan oporavak broja ovih projekata što ukazuje na stagnaciju priliva SDI. Broj projekata u Albaniji, međutim ukazuje na kolebljivo kretanje karakteristično po rastu broja projekata u periodu 2010-2012. godine, da bi u 2013. godini došlo do značajnog pada ove vrste projekata što ukazuje na smanjen interes stranih unvestitora u ovoj godini. Isti trend kretanja, samo na većem broju projekata uočljiv je i kada je u pitanju Makedonija kao destinacija ovih projekata. Nešto drugačije kolebanje uočava se analizom broja ovih projekata u $\mathrm{BiH}$ u kojoj je uočljiv rast projekata u 2010 i 2011. godini ali već 2012 i 2013. godini karakteristična je po padu broja ovih projekata. Srbija, međutim, ima stabilan i kontinuiran rast broja grinfild projekata tokom celog analiziranog perioda, što je izdvaja iz grupe navedenih i analiziranih zemalja u kojima su varijacijekolebanja, karakteristika kretanja broja grinfild projekata. Ovakav kontinuitet ukazuje i na to da interes stranih investitora raste kada je u pitanju Srbija kao destinacija ovih projekata.

Analizirajući vrednost grinfild projekata u zemljama u tranziciji i jugo-istočnoj Evropi uočljivo je takođe kolebanje i promenljivost vrednosti ovih projekata $u$ analiziranim zemljama (Tabela 3.).

Analiza vrednosti grinfild projekata na nivou ekonomija u tranziciji (ukupno), ukazuje na to da nakon pada vrednosti nakon 2009. godine u 2010. godini, oporavak ove vrste investiranja vidljiv je u 2011. godini, dok već 2012 i 2013. godine dolazi dolazi do pada vrednosti ovih projekata i to za $32 \%$ u 2012. godini u odnosu na 2011. godinu i čak 52\% u 2013. godini u odnosu na 2011. godinu. Na globalnom nivou zemalja u tranziciji ovakav pad ukazuje na slabljenje interesa stranih investitora što se može pripisati svetskoj ekonomskoj krizi i problemima u kojima se trenutno nalaze razvijene ekonomije. Međutim, analiza vrednosti grinfild projekata u zemljama jugoistočne-evrope u tranziciji ukazuje na drugačije kretanje kada je u pitanju ovaj region. Nakon pada vrednosti investiranja nakon 2009. godini uočljiv je oporavak investiranja u 2011 i 2012. godini u odnosu na 2010. godinu. Međutim, pad investiranja je zabeležen u 2013. godini.

Analizirajući zemlje u tranziciji jugo-istočne Evrope, uočiće se različita kretanja od zemlje do zemlje i iz godine u godinu analiziranog perioda. Nakon 2009. godine, u Crnoj Gori, vrednost grinfild investicija raste u 2010 i 2011. godini, ali beleži pad u 2012. godini uz rast vrednosti gringild investicija u 2013. godini. Imajući u vidu isti broj projekata u 2012 i 2013. godini a istovremeno rast grinfild investicija u 2013. godini u odnosu na 2012. godinu očigledno je da se radi o rastu vrednosti po jednom grinfild projektu.

Albanija beleži rast vrednosti GI u 2011. godini nakon pada posle 2009 u 2010. godine, ali posle rasta u 2011. godini sledi nagli pad GI i to za $46 \%$ u 2012. godini u odnosu na 2011. godinu i čak devet puta u 2013. godini u odnosu na 2011. godinu. Makedonija, ima nešto bolju situaciju u odnosu na Albaniju, obzirom da ima rast priliva GI 2011 i 2012. godini ali 2010. i 2013. godinu karakteriše pad priliva grinfild investicija. Identično kretanje vrednosti grinfild projekata, analiza pokazuje kada je u pitanju $\mathrm{BiH}$, tj. rast broja projekata u 2011 i 2012. godini, ali u 2010. i 2013. godini uočljiv je pad broja ovih projekata. Srbija i u ovom slučaju ima najstabilnije kretanje broja projekata GI jer beleži stalni rast u periodu 2009-2012. godine, dok je u 2013. godini zabeležen pad za 17\% u odnosu na 2012. godinu.

Interes stranih investitora izražen je i kroz broj grinfild projekata po sektorima privrede što je prikazano u Tabeli 4 .

U ovoj analizi izdvojeno je po pet delatnosti koje su karakteristične po intenzitetu investiranja i interesu stranih investitora, a sa stanovišta broja broja grinfild projekata i njihove vrednosti. Analiza kretanja broja grinfild projekata na globalnom nivou zbira svih sektora privrede ukazuje na rast broja ovih projekata u periodu 2009-2011. godina, ali i na pad broja ovih projekata u 2012 i 2013. godini. Primarni sektor privrede nakon pada u 2010. godini u odnosu na 2009. godinu pokazuje blag oporavaku u 2011. godini, ali već u 2012. i 2013. godini dolazi do pada broja investiranih grinfild projekata. Struktura primarnog sektora na osnovu broja grinfild projekata ukazuje da je investirano u daleko veći broj projekata u delatnostima rudarstva, eksploatacije kamena i petroleja, nego u delatnosti poljoprivrede, lova, ribolova i šumarstva. Identično je kretanje broja grinfild projekata i u sektoru proizvodnje na nivou zbira svih delatnosti. Naime, posle rasta broja ovih projekata u period 2009-2011. godine, u 2012. i 2013. godini dolazi do pada broja grinfild projekata. Analiza broja projekata po delatnostima u okviru sektora proizvodnje, zkazuje na na to da je najveći broj

\begin{tabular}{|c|c|c|c|c|c|}
\hline Region/država & 2009 & 2010 & 2011 & 2012 & 2013 \\
\hline Ekonomije u tranziciji & 54926 & 52067 & 57736 & 39389 & 27868 \\
\hline Jugo-Istočna Evropa & 6192 & 5241 & 7464 & 7568 & 5851 \\
\hline Crna Gora & 120 & 380 & 436 & 355 & 613 \\
\hline Albania & 124 & 68 & 525 & 288 & 57 \\
\hline Makedonija & 763 & 470 & 956 & 1179 & 579 \\
\hline Bosna i Hercegovina & 1368 & 283 & 1253 & 1287 & 880 \\
\hline Srbija & 3816 & 4040 & 4295 & 4459 & 3721 \\
\hline
\end{tabular}

Tabela 3. Vrednost grinfild projekata po destinacijama (U milionima USD)

Izvor: UNCTAD (2014) 


\begin{tabular}{|c|c|c|c|c|c|}
\hline Sektor privrede & 2009 & 2010 & 2011 & 2012 & 2013 \\
\hline Ukupno-za sektore privrede & 14738 & 15141 & 16064 & 14215 & 13919 \\
\hline Primarni sektor & 305 & 157 & 169 & 94 & 85 \\
\hline Poljoprivreda, lov, ribolov, šumarstvo & 8 & 1 & 2 & 1 & 3 \\
\hline Rudarstvo, eksploatacija kamena, petrolej & 297 & 156 & 167 & 93 & 82 \\
\hline Proizvodnja-ukupno za sve delatnosti & 6797 & 7666 & 7924 & 6576 & 6585 \\
\hline Tekstil, odeća i koža & 1152 & 1275 & 1157 & 1023 & 1247 \\
\hline Električna i elektronska oprema & 999 & 1247 & 1168 & 974 & 868 \\
\hline Motorna vozila i ostala saobraćajna sredstva & 893 & 1082 & 1160 & 956 & 863 \\
\hline Mašine i oprema & 837 & 860 & 1032 & 833 & 817 \\
\hline Hemija i hemijski proizvodi & 814 & 867 & 861 & 695 & 725 \\
\hline Usluge & 7636 & 7318 & 7971 & 7545 & 7249 \\
\hline Društvene, socijalne i lične uslužne delatnosti & 2962 & 3121 & 3639 & 3656 & 3460 \\
\hline Zdravstvene i socijalne usluge & 1362 & 1312 & 1447 & 1201 & 959 \\
\hline Obrazovanje & 958 & 957 & 990 & 995 & 1065 \\
\hline Poslovne usluge & 885 & 801 & 801 & 705 & 825 \\
\hline Finansije & 447 & 331 & 382 & 273 & 309 \\
\hline
\end{tabular}

Napomena: broj grinfild projekata je u ovoj tabeli prikazan na globalnom nivou sa ciljem da se ukaže na osnovne pravce ineteresa stranih investitora u odnosu na sektore privrede.

Tabela 4. Broj grinfild projekata po sektorima privrede

Izvor: UNCTAD (2014)

\begin{tabular}{|l|r|r|r|r|r|}
\hline Sektor privrede & 2009 & 2010 & 2011 & 2012 & 2013 \\
\hline Ukupno & 1008273 & 860905 & 902365 & 613939 & 672108 \\
\hline Primarni sektor & 116928 & 56259 & 76020 & 25399 & 28973 \\
\hline Poljoprivreda, lov, ribolov, šumarstvo & 236 & 12 & 116 & 2 & 2166 \\
\hline Rudarstvo, eksploatacija kamena, petrolej & 116693 & 56247 & 75903 & 25398 & 26808 \\
\hline Proizvodnja & 392794 & 450189 & 442348 & 268036 & 258471 \\
\hline Metali i proizvodi od metala & 32566 & 21472 & 28478 & 20656 & 17623 \\
\hline Mašine i oprema & 33760 & 50646 & 45499 & 21855 & 19972 \\
\hline Električna i elektronska oprema & 50614 & 58857 & 55389 & 27367 & 23869 \\
\hline Industrija preciznih instrumenata & 55126 & 67087 & 63820 & 30782 & 27246 \\
\hline Motorna vozila i ostala saobraćajna sredstva & 67532 & 69106 & 64931 & 40365 & 38736 \\
\hline Usluge & 498551 & 354456 & 383997 & 320504 & 384664 \\
\hline Finansije & 34666 & 30711 & 27833 & 20286 & 25406 \\
\hline Poslovne usluge & 44249 & 42828 & 40765 & 36086 & 32415 \\
\hline Obrazovanje & 71165 & 43872 & 46936 & 49986 & 38801 \\
\hline Zdravstvene i socijalne usluge & 74330 & 62385 & 71984 & 58293 & 59063 \\
\hline Društvene, socijalne i lične uslužne delatnosti & 89042 & 62605 & 72689 & 60477 & 93510 \\
\hline
\end{tabular}

Tabela 5. Vrednost grinfild projekata po sektorima privrede (u milionima USD)

Izvor: UNCTAD (2014)

projekata investiran u delatnosti tekstila,odeće i kože, dok je najmanji broj ovih projekata realizovan u oblasti hemije $i$ hemijskih proizvoda.

U sektoru usluga, kao i u prethodna dva sektora, maksimum broja realizovanih grinfild projekata dostignut je 2011. godine, dok je u 2012. i 2013. godini zabeležen pad broja ovih projekata. Od pet analiziranih i prikazanih delatnosti najintezivnijih po broju realizovanih grinfid projekata, može se izdvojiti delatnost društvenih, socijalnih i ličnih uslužnih delatnosti kao delatnost sa najvećim brojem realizovanih projekata. Najmanji broj realizovanih projekata je u delatnosti finansijskih usluga.

Vrednost realizovanih i investiranih vrednosti grinfild projekata takođe ukazuje na pravce interesa stranih investitora, što je prikazano podacima u Tabeli 5 .
Nakon pada vrednosti realizovanih grinfild projekata po sektorima privrede, maksimalni rast GI dostignut je u 2011. godini, nakon čega dolazi do pada vrednosti GI u 2012. godini, ali se u 2013. godini uočava oporavak rasta ove vrste investicija. Analiza investiranih vrednosti po sektorima privrede pokazuje das u najmanja investiciona ulaganja ostvarena u primarni sektor privrede i to posle oporavka u 2011. godini, dolazi do naglog pada investiranja u ovaj sektor, za $67 \%$ u 2012. dodini u odnosu na 2011. godinu i za 62\% u 2013.g. u odnosu na 2011. godinu. Vrednost grinfild investicija u ovaj sektor iznosi 303,6 miliona USD, što je svega 7\% ukupnih grinfild investicija. Sektor proizvodnje prema iznosu ulaganja u GI ukazuje na veći interes stranih investitora, jer vrednost grinfild projekata u ovom sektoru iznosi 1,812 milijardi USD što je šest puta veći iznos investiranja 
nego u primarni sektor privrede i 45\% ukupne vrednosti grinfild investicija. Maksimum vrednosti GI u sektor proizvodnje dostignut je 2010.godine. Nakon ove godine uočljiv je konstantan pad vrednosti GI u ovom sektoru i to u 2013. godini za $43 \%$ u odnosu na masimum iz 2011.godine. Analiza vrednosti GI po delatnostima pokazuje da su investitori najveći interes pokazali u delatnosti motornih vozila i ostalih saobraćajnih sredstava, dok je najmanja vrednost grinfild investicija iskazana u delatnosti metala i proizvoda od metala. Najveća vrednost realizovanih GI ostvarena je u sektoru usluga i to u iznosu od 1,942 milijarde USD, što je $48 \%$ ukupne vrednosti grinfild investicija pri čemu je najveća vrednost grinfild projekata ostvarena u delatnosti društvene, socijalne i lične uslužne delatnosti, a najmanja ulaganja su ostvarena u delatnosti finansijskih usluga.

Interes stranih investitora određen je i rizicima koji imaju značajan uticaj na donošenje investicionih odluka, posebno kada su u pitanju grinfild investicije u kontekstu SDI. Prema (EIU 2007) strani investitori od 17 navedenih rizika kao najveće rizike investiranja u zemlje u ekonomijama u razvoju i tranziciji sa negativnim uticajem ističu: politički rizik, korupciju, stanje infrastrukture i prinudno sprovođenje ugovora, odnosno slabost pravosuđa. Kao rizike najmanjeg intenziteta negativnog uticaja, strani investitori označavaju nezainteresovanost u ulaganje u zemlje brzog razvoja, troškove radne snage, nedostatak pristupa izvorima finansiranja i poreske stope.

\section{REZIME}

Grinfild investicije su jedan od ključnih faktora razvoja ekonomije imajući u vidu njihove osnovne karakteristike, posebno u zenljama u tranziciji, zbog njihovog specifičnog ekonomskopolitičkog položaja. Interes stranih investitora za investiranjem u ekonomijama u razvoju, nastavljen je i u 2013. godini. Analiza kretanja grinfild investicija po destinacijama zemalja u tranziciji, a po kriterijumu broja projekata i njihove vrednosti, ukazuje na godišnja kolebanja, dok se stabilno rastuće kretanje navedenih parametara uočava jedino kada je u pitanju Srbija. Interes stranih investitora, izražen kroz analizu navedenih parametara, nedvosmisleno je u konstantnom porastu kada je u pitanju Srbija kao destinacija grinfild investicija. U slučajevima ostalih zemalja u tranziciji jugo-istočne Evrope interes stranih investitora varira $u$ analiziranom periodu i izražen je različitim brojem projekata i njihovom vrednošću posmatrano iz godine u godinu. Urađena anliza otvara i određena pitanja na koja bi odgovor mogla dati dublja analiza i dodatnih parametara čime bi se ukazalo na uzroke ovakvih varijacija interesa stranih investitora, kao i koji sektori privrede i delatnosti su najinteresantnije destinacije za ovu vrstu investicija. Isto tako, dalja analiza bi trebala da ukaže i na rešenje problema rizika koji strani investitori ističu kao značajna ograničenja prilikom donošenja investicionih odluka. Zemlje u tranziciji jugo-istočne Evrope, time i Srbije, bi morale da stvaraju ambijent za strano investiranje time što će stvarati političku stabilnost, nastaviti borbu sa korupcijom, uspostaviti stabilniji pravni sistem i preispitati stanje infrastrukture kao neophodnog uslova investiranja. Analiza koja je urađena u ovom radu daje početne elemente za osnovne smernice i prioritete investicione politike Srbije, ali i zemalja u okruženju koje se nalaze u stanju tranzicije.

\section{LITERATURA}

Begovićm B., Mijatović, B., Paunović, M., \& Popović, D. (2008). Grinfild strane direktne investicije u Srbiji. Beograd: Centar za liberalno-demokratske studije. Preuzeto sa: http://www. clds.rs/newsite/Grinfild\%20SDI\%20monografija\%20prelom\%20srpski\%20vf.pdf

Vidas-Bubanja, M. (1998). Metode i determinante stranih direktnih investicija. Beograd: Institut ekonomskih nauka.

Cvetković, P. (2004). O efektima stranih investicija: razlika između stvarnosti i predrasuda. Kvalitet medunarodnih odnosa, svest o regionalnom identitetu i mogućnosti saradnje $i$ integracije na Balkanu: Zbornik radova. Niš: Institut za sociologiju Filozofskog fakulteta. Preuzeto sa: http://www. npao.ni.ac.rs/files/584/03_Zbornik_Kvalitet_medjuetnickih_odnosa_svest_o_regional_8085c.pdf

UNCTAD. (2014). World Investment Report 2014: Investing In the SDGs-An Action Plan. Preuzeto sa: http://unctad.org/ en/PublicationsLibrary/wir2014_en.pdf 